\title{
Laboratory investigation of earthquake lightning due to landslide
}

\author{
Yuji Enomoto ${ }^{1 *} \mathbb{0}$, Tsuneaki Yamabe ${ }^{1}$, Kazuyuki Mizuhara ${ }^{2}$, Shigeki Sugiura ${ }^{3}$ and Hitoshi Kondo ${ }^{3}$
}

\begin{abstract}
Several laboratory experimental studies of photoemission characteristics of rocks as they fracture have been conducted to elucidate the mechanism of earthquake lightning (EQL). In most of these studies, granite, which exhibits remarkable photoemission, is widely used to explain the mechanism attributed to the exoelectron emission effect or piezo-induced effect of quartz, a constituent mineral of granite. Photoemission induced by rock fracturing has been observed prominently during landslides caused by earthquakes. According to the literature on historical earthquakes, landslide-induced EQL was witnessed even at locations where quartz was not present. In this study, we therefore studied the physicochemical characteristics of photoemissions associated with impact shear fractures in various rocks, selected based on historical earthquake records of landslide EQL. As a result, we could highlight various physicochemical processes associated with the frictional heating generated during shear impacts between rocks.

Keywords: Photoemission, Rock fracture, Landslide, Earthquake lightning (EQL)
\end{abstract}

\section{Introduction}

Fracto-emission is a phenomenon in which charged particles and photons are emitted from a newly created fracture surface upon the rupture of hard and brittle solids, such as ceramics, polymers, and rocks (e.g., Dickinson et al. 1981, 1988; Enomoto and Chaudhri 1993). In the area of earthquake research, photoemission from fracturing rocks has been observed in relation to earthquake lightning (EQL), which is often observed before, during, or after an earthquake (Musya 1932; Enomoto 1998). In laboratory experiments, granite containing quartz, which exhibits a piezoelectric effect, has been widely used due to the ease of detecting its photoemission (Brady and Rowell 1986; Kawaguchi 1998; Kato et al. 2010). These results led to proposed models for the exoelectron bombardment mechanism (Brady et al. 1986) or piezoelectricinduced effect (Ikeya and Takagi 1996).

Lightning from fracturing rocks can be directly observed not when rock rupture occurs at a deep focal

\footnotetext{
*Correspondence: enomoto@shinshu-u.ac.jp

1 Fii, Ueda Campus, Shinshu University, 3-15-1 Tokida, Ueda, Nagano

386-8567, Japan

Full list of author information is available at the end of the article
}

zone, but when landslides due to mountain collapse occur in association with earthquakes. Because the stratum of the Japanese archipelago is complex and has many active faults, historical earthquake records in Japan reveal several cases where EQL was eye-witnessed in association with landslides. However, these mountains were not necessarily composed of granite, but other kinds of rock. Therefore, we conducted impact fracture experiments on the rocks that composed the mountain strata based on the evidence of landslide EQL found in historical earthquake records, and investigated photoemission characteristics in terms of the physicochemical nature of these rocks.

\section{Materials and methods}

Historical records on landslide EQL

We surveyed the descriptions of EQL in the Japan Historical Earthquake Archives (e.g., ERI 1981-1994; Musya 1932) to find at least 5 eye-witness accounts out of 55 reports of EQL caused by landslides (Enomoto 1998). In consideration of the geology and the lightning characteristics for these seven events, the three landslide EQL events listed below were selected to clarify the mechanism. Figure 1a shows the locations of three selected 

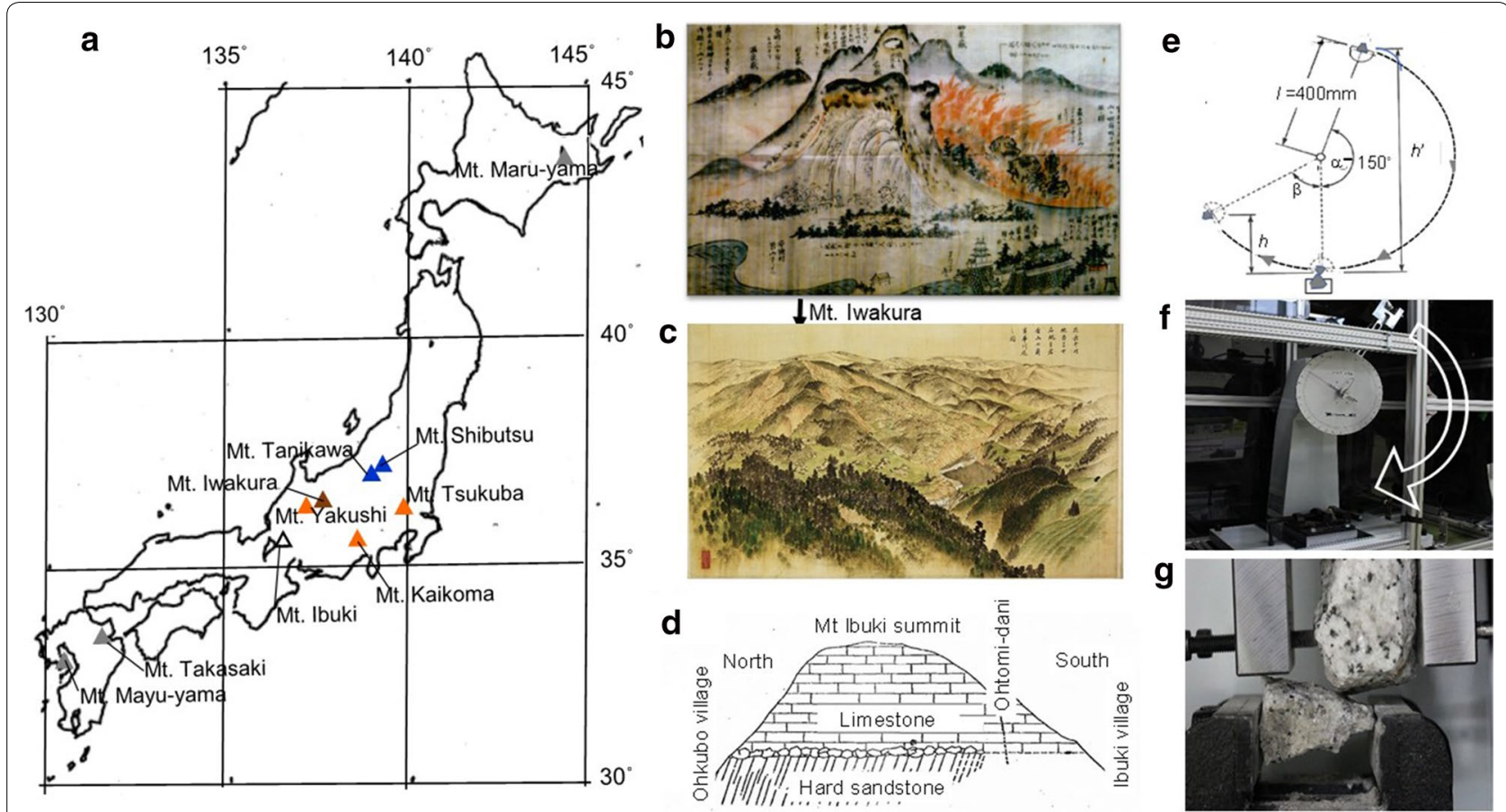

Fig. 1 a Locations of the mountains and their mountain strata (red triangle, granite; white triangle, limestone; grey triangle, pyrostatic rocks; brown triangle, sandstone/conglomerate/rhyolite tuff breccia; blue triangle, serpentinite). b Picture of the collapse of Mayu-yama with flames (in a collection of ERI, University of Tokyo). c Picture of the landslide at Mt. Iwakura sketched by S. Aoki (in a collection of Sanada Treasure Museum). d Sketch of geological structure of Mt. Ibuki by Koto (1910), with Japanese terms translated into English. e Configuration and f equipment view of Charpy impact tester and $\mathbf{g}$ test rocks fixed to both holders at the bottom and the pendulum (upper)

mountains where landslide EQL was recorded, as well as other mountains composed of granite or serpentinite as discussed later.

1. The Unzen earthquake $(M=6.4 \pm 0.2)$ occurred at about 19:00 local time (LT) on 21 May 1792 in the Unzen volcanic area in western Kyushu. A gigantic landslide was induced by the earthquake on the eastern slope of Mayu-yama (819 m above sea level) in the Unzen volcanic area which is composed of pyroclastic rock. A huge amount of soil and rocks with flames rushed into the Ariake Bay, generating a large tsunami. A contemporaneous drawing of the event is shown in Fig. 1b. Because it was witnessed as a severe pyroclastic flow, people at that time thought Mayuyama had a volcanic eruption. Later studies, however, indicated that this event was due to landslide collapse of Mt. Mayu-yama (Ohta 1969; Katayama 1974).

2. In the 1847 M7.4 Nagano (Zenkoji) earthquake, which occurred at about 21:30 LT on 8 May, the quake caused many landslides and collapses, mainly in the western mountains of Nagano City. In particular, a collapse that occurred on the southwest side of Mt. Iwakura (764 $\mathrm{m}$ above sea level), about $12 \mathrm{~km}$ southwest of Nagano City, was the largest.
Figure 1c is a picture of Mt. Iwakura drawn by Sekkei Aoki when he visited the disaster-stricken area in 1850-1851 with the lord of the Matsushiro domain, who ruled the area at the time. Both the left and right sides in the figure collapsed from near the mountaintop and the landslide on the right side (SW direction) was the largest: it was $750 \mathrm{~m}$ wide and about $1300 \mathrm{~m}$ long (Nagano-ken 1997). The geology of Mt. Iwakura is mainly sandstone and conglomerate, and rhyolite tuff breccia is sandwiched in irregular forms (Nagano-ken 1997). It should be noted that when the collapse occurred, every corner inside the houses at the foot of Aniwa village were illuminated as bright as daytime.

3. In the 1909 M6.7 Anegawa (Kono) earthquake in Shiga prefecture, a limestone cliff collapsed on the west side of Mt. Ibuki (1377 m above sea level), dust flew up, the mountain summit could not be seen from the foot, and the area became dark, even in the daytime, 15:31 LT. At that time, many of the residents at the foot witnessed EQL. They, therefore, thought that the earthquake was caused by a volcanic eructation of Mt. Ibuki. The survey report by Koto (1910) mentioned that the cause of EQL was not well understood. His sketch of a geological structure, that is, 
limestone of the collapsed west side of Mt. Ibuki, is shown in Fig. 1d.

Of the 5 landslide EQL records mentioned above, the other two are landslide EQL of Mt. Takasaki $(628 \mathrm{~m}$, Oita) in the 1 Sept. 1596 M7.0 $\pm 1 / 4$ Keicho-Bungo earthquake and that of Mt Maru-yama (226 m, Hokkaido) in the 29 May 1938 M6.8 Kussyaro-ko earthquake. Both mountains are lava domes with a history of volcanic activity in the past. The mechanism of the landslide EQL of these mountains might, therefore, be similar to the that of Mayu-yama in the 1972 Unzen earthquake as noted in 1).

\section{Charpy impact tests}

Because we expect landslide EQL to be caused by photoemission that occurs due to collisional shear fractures between rocks as they fall down a slope, an impact shear fracture type test is more appropriate as an experimental method to simulate the process than an uniaxial compression fracture test or a three-point bending fracture test. We therefore used a Charpy impact tester as shown in Fig. 1e-g. This test in industry is a standardized high strain-rate test which measures a material resistance for fracture (e.g., Leis 2013). The present Charpy impact test involves striking a rock sample fixed in a bottom holder with a pendulum containing the same kind of rock in its holder at a predetermined height. The as-received rock samples were cut to an appropriate size so that they could be fixed to both holders of the Charpy impact tester. As shown in Fig. 1g, the two rock samples were set to engage to a depth of 2-5 mm wide at impact. The arm length was $400 \mathrm{~mm}$, and the swing angle $a$ was $150^{\circ}$. The speed $v$ and the kinetic energy $1 / 2 \mathrm{Mv}^{2}$, where $M$ is pendulum mass, at impact were $4.0 \mathrm{~m} / \mathrm{s}$ and $25 \mathrm{~J}$, respectively. The contact time during impact was about $1.3 \mathrm{~ms}$. To carry out photography and spectroscopy, the test was performed in the room air with the entire test apparatus enclosed by a dark curtain so as to prevent light leakage.

Rock samples used in the present tests were coursegrained granite (Inada, Ibaraki), pyroclastic rock (Mayuyama, Nagasaki), biotite-bearing rhyolite (Nagawa, Nagano), limestone (Mt. Ibuki, Shiga), and serpentinite (Miyatsu, Kyoto). All these rocks are in ambient state which contain about $0.1 \mathrm{wt} \%$ water.

Light photoemitted during the collision was photographed by a digital camera (Canon EOS Kiss X7i) with an ISO sensitivity of 25,600 and the shutter was opened for $1 \mathrm{~s}$ from just before to just after the collision. Meanwhile, the spectrum measurements were conducted by means of a spectroradiometer (CS-2000A, Konica Minolta) with a close-up lens for measurement of smaller areas where photoemission occurred, in the wavelength range from 380 to $780 \mathrm{~nm}$ and at a wavelength resolution of $0.9 \mathrm{~nm} /$ pixel. The spectrometer was also used to measure the spectrum of thermoluminescence from limestone.

To examine flammable gases such as hydrocarbons and $\mathrm{H}_{2} \mathrm{~S}$ contained in the rock samples, we employed thermal desorption spectroscopy-mass spectrometry (TDS-MS). A rock sample was cut to a size of $15 \times 15 \times 4 \mathrm{~mm}$ and heated at a rate of $20{ }^{\circ} \mathrm{C} / \mathrm{min}$ using an infrared heating furnace in a vacuum vessel. Then, the released gases were analyzed using a quadrupole mass spectrometer.

\section{Results and discussion}

Figure $2 \mathrm{a}-\mathrm{d}$ shows photoemission images during the collision of the rock samples. These images show that the unique appearance and intensity of photoemission depend on each rock.

Note that since the impact period, comparable to photoemission period, is $1.3 \mathrm{~ms}$ which is much shorter than the exposure period of $1 \mathrm{~s}$, the intensity distribution of photoemission is less affected by the impact hammer speed. Granite showed an intense whitish spark streak during impact (Fig. 2a). Pyroclastic rock produced a glowing gaseous red lightning around the hotspot (Fig. 2b). Biotite-bearing rhyolite showed an orangecolored lightning streak (Fig. 2c). Limestone showed a weak red color on the newly created fracture surface (Fig. 2d). Serpentinite showed no photoemission, and thus it is not shown in the figure. The red, green, and blue (RGB) intensities on a scale of 0 to 255 for photoemissions from the brightest part at impact for each rock and from a position off the hotspot for granite and rhyolite are also shown in these figures. The order of the photoemission intensity was granite $>$ biotite rhyolite $>$ pyroclastic rock > limestone, with no emission from serpentinite (not shown In Fig. 2). The difference in the shape, color, and RGB ratio of the photoemission as seen in Fig. 2 suggests that the physicochemical mechanism differs from rock to rock. Next, the mechanisms of photoemission from each rock were investigated, and are discussed in detail.

\section{Granite}

Photoemission from granite was the brightest among the tested rocks, and was the only one that could be captured upon impact using a spectroradiometer, as shown in Fig. 3a. The spectral intensity increased continuously as the wavelength became longer, which is characteristic of black-body radiation: the peak of the spectrum should be in the far-infrared region, but the temperature can be inferred from the intensity ratio for two wavelengths, $\lambda(740 \mathrm{~nm}) / \lambda(620 \mathrm{~nm})=3.6$, assuming that the tail can be expressed by Planck's law (Fig. 3b). We used the results in 


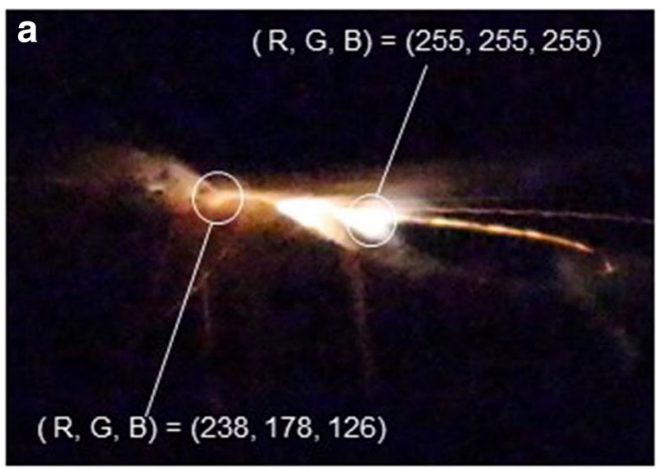

$10 \mathrm{~mm}$

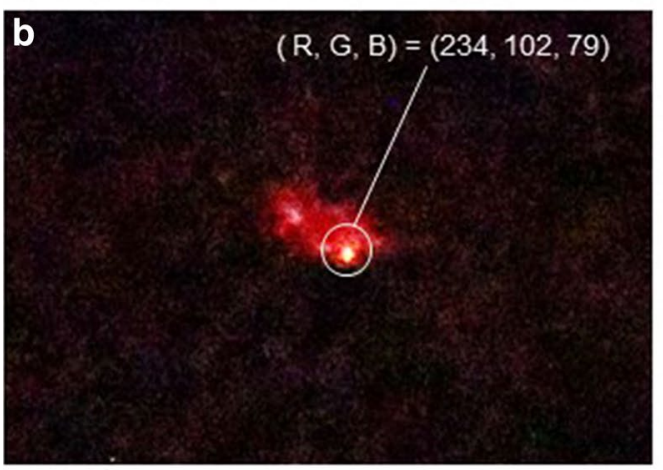

$5 \mathrm{~mm}$

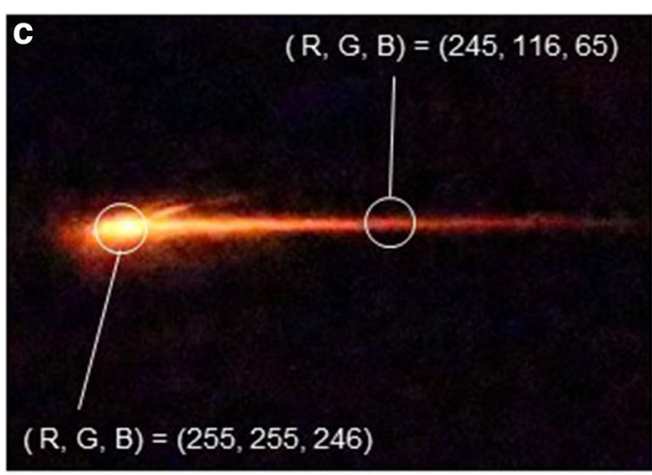

$10 \mathrm{~mm}$

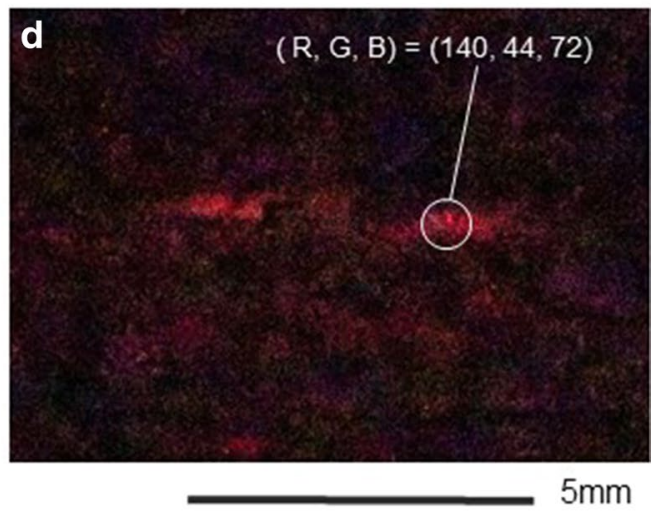

Fig. 2 Photographs of photoemissions from a granite, $\mathbf{b}$ pyroclastic rock, $\mathbf{c}$ biotite-bearing rhyolite, and $\mathbf{d}$ limestone. Note that the scale in $\mathbf{b}$ and $\mathbf{d}$ are enlarged with increased brightness to make the photoemission patterns easier to see. The RGB intensities on a scale of 0 to 255 are also noted in a-d. All RGB values are based on the original brightness of the photos when they were taken

Fig. 3c to estimate the frictional temperature during collision to be $1750 \mathrm{~K}\left(=1477^{\circ} \mathrm{C}\right)$.

The TDS-MS analysis showed that any flammable gases are less contained in the granite; therefore, photoemission due to degassing is not possible. At such a high temperature, minute fragments of non-stoichiometric oxides of rock constituents would be ignited when the fragments underwent oxidation reaction and show a continuous radiation spectrum.

In contrast, many spectral lines appeared in the short wavelength range around $380-420 \mathrm{~nm}$, which might be attributed to photoemission from vibrationally or electrically excited states of the constituent elements of the granite; that is, when the temperature rises to 250 $400{ }^{\circ} \mathrm{C}$, lone-pair electrons captured by lattice defects in the granite are thermally released. In a previous experimental study (Enomoto et al. 1993), measurements of thermally stimulated exoelectrons (TSEEs) emitted from constituent minerals, including quartz, feldspar, and biotite in granite (Inada, Ibaraki), indicated notable emissions from biotite. The energy of TSEEs should be as low as about $1 \mathrm{eV}$, but when the rock breaks, an intense electric field is likely created in the small gap between both cracked new faces due to charge separation (Enomoto and Hashimoto 1990; Enomoto and Chaudhri 1993). The electric field can accelerate exoelectrons to gain enough energy to ionize atmospheric molecules and other species in the rock minerals, resulting in the generation of a plasma streak (Brady and Rowell 1986; Enomoto and Hashimoto 1990). That is, according to Paschen's law, which gives the voltage necessary to form a discharge between two electrodes in a gas as a function of pressure $p$ and gap length $d$, the minimal breakdown voltage $V$ for $p d=7.5 \times 10^{-6} \mathrm{~m}$ atm, where $V$ is $327 \mathrm{~V}$ in air at standard atmosphere pressure $(p=1 \mathrm{~atm})$ at a distance of $7.5 \mu \mathrm{m}$. This condition could be achieved at the instant when the rock is fractured by the present Charpy impact experiment (Enomoto and Chaudhri 1993).

Japan has many mountains composed of granite, such as Mt. Kaikoma, Mt. Yakushi, and Mt. Tsukuba in (see Fig. 1a). However, our survey showed that there are few Japanese historical earthquake records on EQL due to granite landslides on such mountains (e.g., ERI 19811994; Musya 1932; Enomoto 1998). 

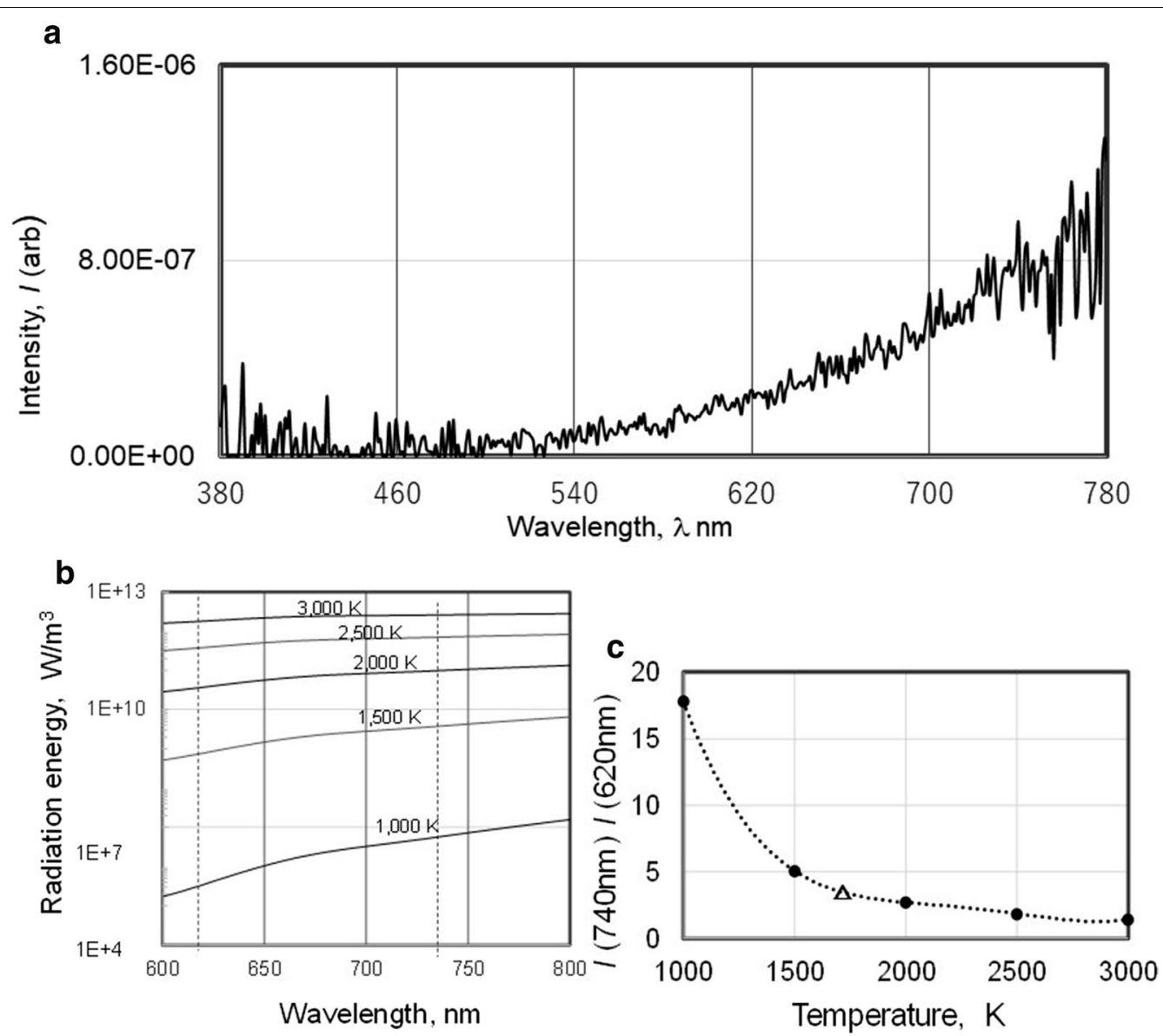

Fig. 3 a Photoemission spectrum upon impact for granite. b Planck's black-body radiation energy spectrum in the wavelength range from 600 to $800 \mathrm{~nm}, \mathbf{c} /(740 \mathrm{~nm}) / /(620 \mathrm{~nm})$ vs. $T(\mathrm{~K})$, black circle: /(740 nm)//(620 nm) determined from Planck's law for temperatures curves of $1000-3000 \mathrm{~K}$; white triangle: $/(740 \mathrm{~nm}) / /(620 \mathrm{~nm})=3.6$, determined from the spectrum shown in a

\section{Pyroclastic rock}

The pyroclastic rock was subjected to the TDS-MS analysis. The typical mass spectrum is shown in Fig. 4a for pyroclastic rock, showing $\mathrm{H}_{2} \mathrm{O}$, lower hydrocarbons showing complex cracking patterns like as $\mathrm{C}, \mathrm{CH}, \mathrm{CH}_{4}$, $\mathrm{C}_{2} \mathrm{H}_{2}, \mathrm{C}_{2} \mathrm{H}_{4}$, etc., $\mathrm{H}_{2} \mathrm{~S}$, and $\mathrm{CO}_{2}$ peaks, which are components of typical volcanic gases (Sakata et al. 1996). It is noted that the amount of hydrocarbon outgassing increases about 20 times as the temperature rises from 250 to $450{ }^{\circ} \mathrm{C}$, which indicates that it is promoted by heating. Both hydrocarbons and $\mathrm{H}_{2} \mathrm{~S}$ are flammable gases, but the ignition temperature for lower hydrocarbons is $537-630{ }^{\circ} \mathrm{C}$, which is higher than that for $\mathrm{H}_{2} \mathrm{~S}, 260{ }^{\circ} \mathrm{C}$. However, these temperatures could easily be reached by frictional heating during sliding impact. Therefore, $\mathrm{H}_{2} \mathrm{~S}$ first burns due to frictional heating and heats lower hydrocarbons to release carbon and become hot: the carbon produces a red flame, as confirmed in the laboratory test, and shown in Fig. 1b.

\section{Biotite-bearing rhyolite}

Rhyolite has the second-highest photoemission intensity after granite (see Fig. 3c). The B value is slightly smaller than the $R$ and $G$ values. The TDS-MS spectrum of this rock is shown in Fig. $4 \mathrm{~b}$, showing that even when the heating temperature rises from 250 to $500{ }^{\circ} \mathrm{C}$, the peak intensity for lower hydrocarbons remains almost unchanged, unlike those for pyroclastic rock. This may indicate that hydrocarbons were chemisorbed by the rock minerals. Furthermore, the peaks appear periodic with $m / z$ differences of $14\left(\mathrm{CH}_{2}\right)$, so this rock may contain a small amount of mixed hydrocarbons. However, the amount of photoemission from the rhyolite due to the effect of degassing and burning of these hydrocarbons might be small, unlike that for pyroclastic rock. Rather, because the rhyolite contains biotite and quartz with high TSEE activity, the cause of the photoemission is likely to be similar to that of granite, as described above. 


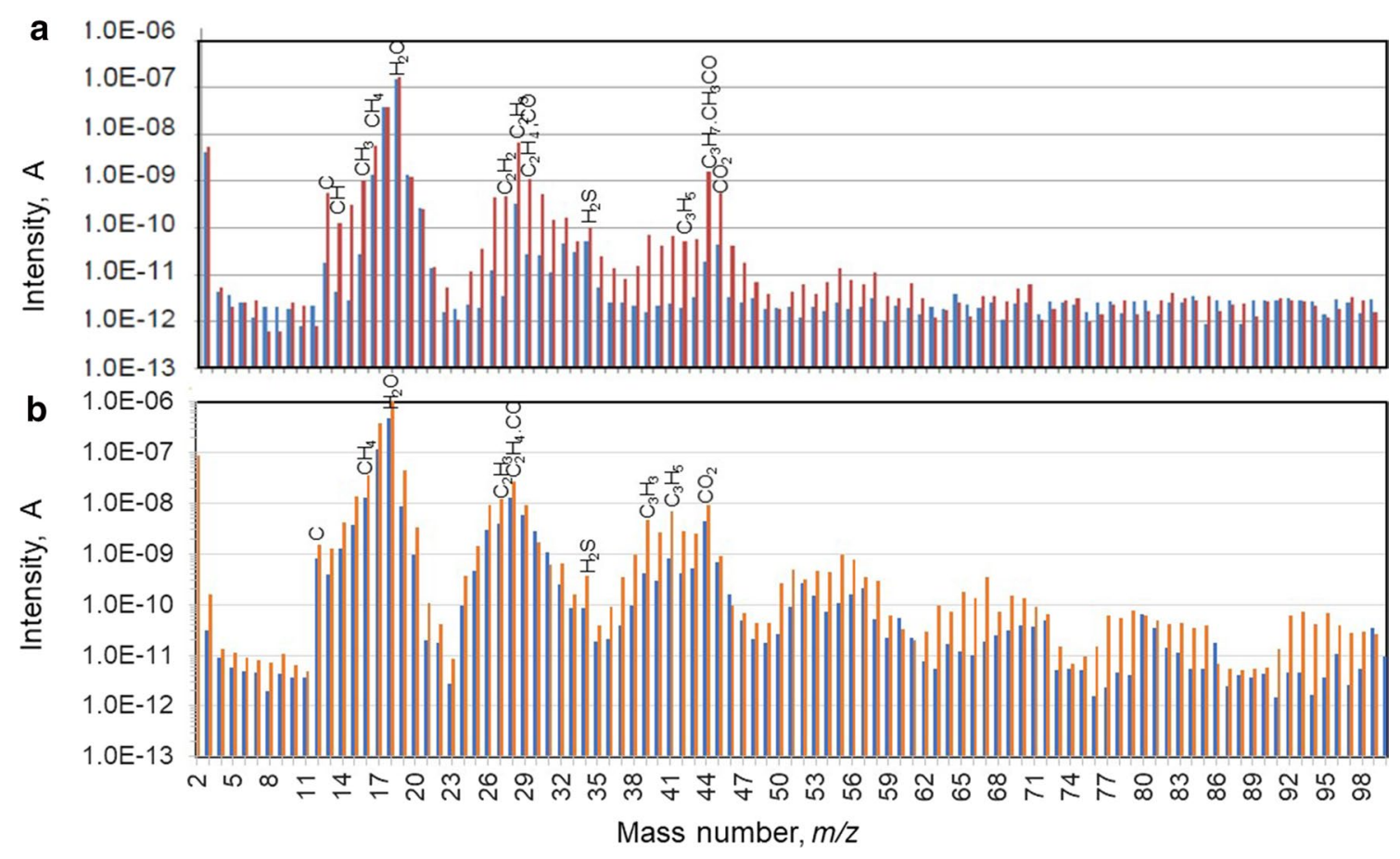

Fig. 4 TDS-MS of a pyroclastic rocks collected from Mayu-yama at temperatures of $250^{\circ} \mathrm{C}$ (blue bars) and $450^{\circ} \mathrm{C}$ (red bars) and $\mathbf{b}$ rhyolite at temperatures of $250^{\circ} \mathrm{C}$ (blue bars) and $500^{\circ} \mathrm{C}$ (red bars)

\section{Limestone}

Limestone is a sedimentary rock composed of calcium carbonate $\left(\mathrm{CaCO}_{3}\right)$ formed mainly from sea shells. Limestone does not contain quartz, biotite, or flammable gases that can cause photoemission. However, it is well known that natural radiation for extended geological ages creates electronically excited (trapped) states in limestone.
Heating allows these trapped states to interact with thermally activated lattice vibrations and rapidly decay into lower energy states, causing the emission of photons, that is, thermoluminescence, TL (Kalita and Chithambo 2019).

The fracture surface, newly created during impact tests, shows red emission due to TL, as seen in Fig. 5c. The red

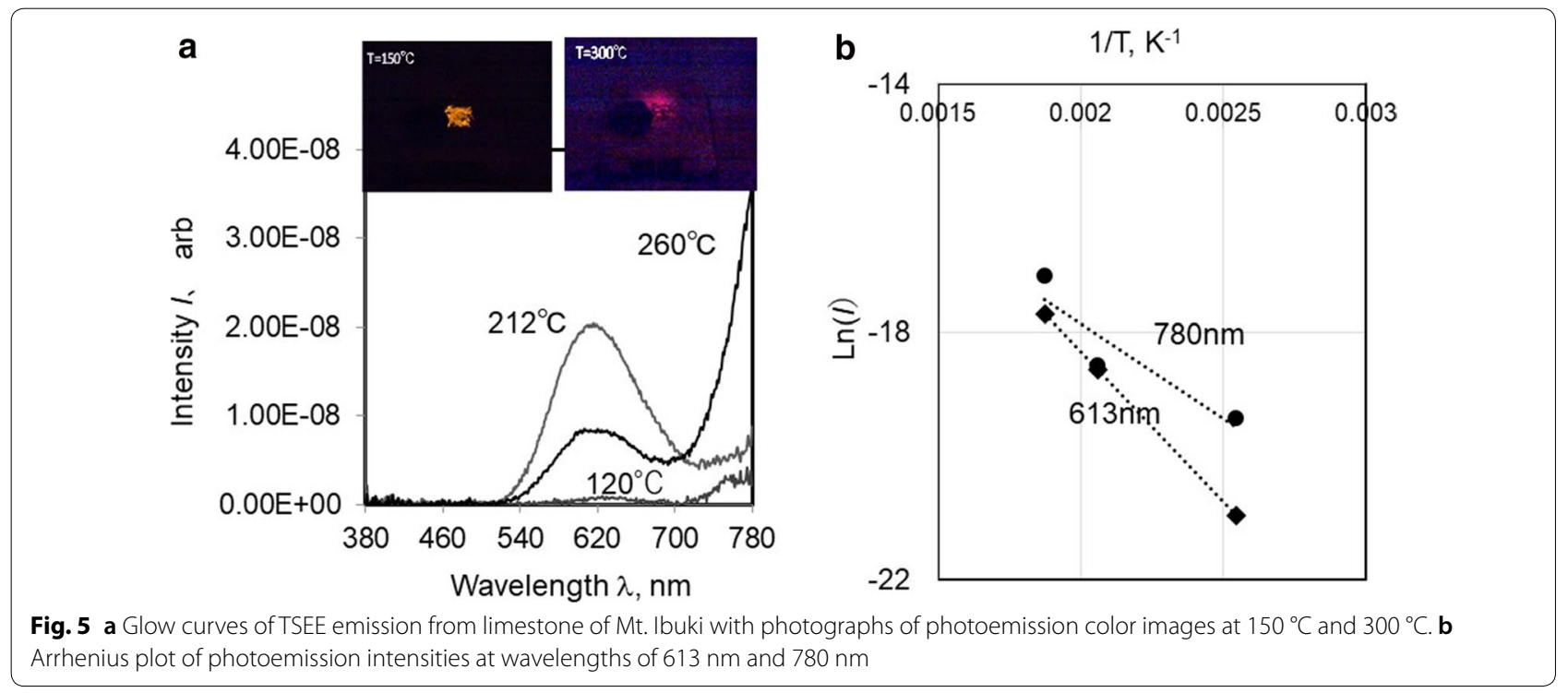


light associated with the collapse of limestone in the 1909 Anegawa earthquake may be the reason why the villagers assumed that the volcano had exploded. To confirm this hypothesis, we conducted TL experiments on the limestone sample.

A thin limestone plate sliced from the as-received sample was heated on a hot plate at a rate of $5{ }^{\circ} \mathrm{C} / \mathrm{min}$ in air in a dark room, and the color and the spectra of the light emitted from the sample were observed by photography and spectroradiometry, respectively. At a temperature of $212{ }^{\circ} \mathrm{C}$, an orange spectrum around $613 \mathrm{~nm}$ was seen, as shown in Fig. 5a, but the red emission at $780 \mathrm{~nm}$ became more intense at around $260{ }^{\circ} \mathrm{C}$. The activation energies for photons released from the trapped sites at wavelengths of $613 \mathrm{~nm}$ and $780 \mathrm{~nm}$ were determined from the Arrhenius plot to be $0.42 \mathrm{eV}$ and $0.27 \mathrm{eV}$, respectively, as shown in Fig. 5b. A temperature of $260^{\circ} \mathrm{C}$ could be easily reached by frictional heating in the present Charpy tests.

\section{Serpentinite}

No photoemission from serpentinite during impact could be confirmed with the present camera sensitivity, although we were able to measure emissions of negatively charged particles (fracto-emissions) accompanying fracture in previous experiments during a uniaxial compression fracture test (Enomoto et al. 1994). It is known that normally the shear-fractured surface of serpentinite contains clay minerals such as montmorillonite and smectite, and thus the rock is often smooth, such that a fault may have a mirror-like luster capable of specular reflection. In the present Charpy test, when the serpentinite was subjected to impact, the impacted surface seemed as smooth as a cleaved surface. Therefore, physicochemical mechanisms might not occur to produce photoemission by thermal stimulation.

What can be predicted from the present laboratory experiments is that no landslide EQL can be witnessed in mountains like as Mt. Tanigawa and Mt. Shibutsu, which are composed of serpentinite. But this prediction cannot be verified yet as there was no such event in historical reports (e.g., ERI 1981-1994; Musya 1932; Enomoto 1998).

\section{Conclusion}

In the present impact fracture tests of rocks, photoemission was observed from granite, pyroclastic rock, rhyolite, and limestone, and the intensity and spectral characteristics depended on the type of rock. Photoemission is affected by the temperature rise due to frictional heating during impact, which leads to discharge by a coupling interaction between TSEEs, high electric potential generation due to charge separation and/or the piezoelectric effect, desorption and combustion of flammable gases, and TL due to electronic transitions from trapped sites. The critical temperature at which these physicochemical processes are operated is in a range of $250-450{ }^{\circ} \mathrm{C}$, and it could be sufficiently excited by frictional heat generated by the present impact tests. The experimental results are consistent with eye-witness testimony of landslide EQL.

\section{Acknowledgements}

We gratefully thank the editor and two anonymous reviewers for their constructive and helpful comments. We would like to thank Konika-Minolta for the use of their spectroradiometer. This work was financially supported by the Genesis Research Institute, Inc.

\section{Author's contributions}

YE planned the research and prepared the manuscript. TY and YE performed the Charpy impact tests, KM conducted TDS-MS analyses. SS and HK contributed to the project administration. All authors read and approved the final manuscript.

\section{Funding}

This project was supported by Genesis Research Institute Inc.

\section{Availability of data and materials}

The datasets used and/or analyzed during the current study are available from the corresponding author on reasonable request.

\section{Competing interests}

The authors declare no competing interests.

\section{Author details}

${ }^{1}$ Fii, Ueda Campus, Shinshu University, 3-15-1 Tokida, Ueda, Nagano 386-8567, Japan. ${ }^{2}$ Department of Mechanical Engineering, Tokyo Denki University, 5 Senjyu-Asahi-Cho, Adachi-ku, Tokyo 120-8551, Japan. ${ }^{3}$ Genesis Research Institute, Inc, 4-1-35 Noritake-Shinmachi, Nishi-ku, Nagoya, Aichi 451-8567, Japan.

Received: 27 April 2020 Accepted: 18 July 2020

Published online: 23 July 2020

\section{References}

Brady BT, Rowell GA (1986) Laboratory investigation of the electrodynamics of rock fracture. Nature 321:488-492. https://doi.org/10.1038/321488a0

Dickinson JT, Donaldson EE, Park MK (1981) The emission of electrons and positive ions from fracture of materials. J. Mater Sci. 16:2897-2908. https ://doi.org/10.1007/BF00552976

Dickinson JT, Langford SC, Jensen LC, McVay GL, Kelso JF, Pantano CG (1988) Fracto-emission from fused silica and sodium silicate glasses. J Vac Sci Technol A 6:1084-1089. https://doi.org/10.1116/1.575646

Earthquake Research Institute (ERI) (1981-1994) Shinshu Nihon Jishin Shiryo, vol 5. Earthquake Research Institute, Tokyo, p 812

Enomoto Y (1998) EQL database and characteristics of EQLs (English translation of Japanese title). Rekishi Jishin 14:45-51 (in Japanese)

Enomoto Y, Chaudhri MM (1993) Fracto-emission during fracture of engineering ceramics. J Am Ceram Soc 76:2583-2587. https://doi. org/10.1111/j.1151-2916.1993.tb03984.x

Enomoto Y, Hashimoto H (1990) Emission of charged particles from indentation fracture of rocks. Nature 346:641-643. https://doi.org/10.1038/34664 $1 \mathrm{a} 0$

Enomoto Y, Akai A, Hashimoto H, Mori S, Asabe Y (1993) Exoelectron emission: possible relation to seismic geo-electromagnetic activities as a microscopic aspect in geotribology. Wear 168:135-142. https://doi. org/10.1016/0043-1648(93)90209-5

Enomoto Y, Shimamoto T, Tsutumi A, Hashimoto H (1994) Transient electric signals prior to rock fracturing: potential use as an immediate earthquake precursor. In: Hayakawa M, Fujinawa Y (eds) Electromagnetic phenomena related to earthquake prediction. Terra Pub, Tokyo, pp 253-259

Ikeya M, Takagi S (1996) Electromagnetic fault for earthquake lightning. Jpn J Appl Phys 35:355-357 
Kalita JM, Chithambo ML (2019) Thermoluminescence and infrared light stimulated luminescence of limestone $\left(\mathrm{CaCO}_{3}\right)$ and its dosimetric features. Appl Rad Isotopes 154:10888. https://doi.org/10.1016/j.aprad iso.2019.108888

Katayama N (1974) Old records of natural phenomena concerning the Shimabara catastrophe. Sci Rept Shimabara Volcano Observ Fac Sci Kyushu Univ 9:1-45 in Japanese

Kato M, Mitsui Y, Yanagitani T (2010) Photographic evidence of luminescence during faulting in granite. Earth Planets Space 62:489-493. https://doi. org/10.5047/eps.2010.02.004

Kawaguchi Y (1998) Charged particle emission and luminescence upon bending fracture of granite. Jpn J Appl Phys 37:3495-3499. https://doi. org/10.1143/JJAP.37.3495

Koto B (1910) Chishitsu-Gaku jo-no-kenchi-niyoru Kono Jishin, Sinsai Yobo Chosa-kai Hokoku (English transl.: Earthquake Disaster Prevention Survey Report) 69:1-15 (in Japanese)

Leis BN (2013) The Charpy impact test and its applications. J Pipeline Eng $12: 183-198$
Musya K (1932) Jishin nitomonau Hakko-Gensyo no Kenkyu oyobi Shiryou. (English Transl., Research on lightening phenomena associated to earthquakes and literatures, Iwanami, 417 (in Japanese with English Abstract) Nagano-ken, Jishin to Doshasaigai Symposium Committee, Zenkoji jishin to Dosha-saigai (English Transl., Zenkoji earthquake and landslides), (1997) https://www.pref.nagano.lg.jp/sabo/manabu/documents/dosyajirei -p-000100.pdf (in Japanese)

Ohta K (1969) Study on the collapses in the Mayu-yama. Sci Rep Shimabara Inst Volcanol Balneol Fac Sci Kyushu Univ 5:6-35 (in Japanese)

Sakata S, Takahashi M, Igari S, Matsuhisa Y, Hoshino K (1996) Geochemical study on the origin of natural hydrocarbons accumulated in volcanic reservoir. Bull Geol Surv Jpn 47:619-642

\section{Publisher's Note}

Springer Nature remains neutral with regard to jurisdictional claims in published maps and institutional affiliations.

\section{Submit your manuscript to a SpringerOpen ${ }^{\circ}$ journal and benefit from:}

- Convenient online submission

- Rigorous peer review

- Open access: articles freely available online

- High visibility within the field

- Retaining the copyright to your article

Submit your next manuscript at $\boldsymbol{\nabla}$ springeropen.com 